\title{
Borsa İstanbul 30 Endeksinde Yer Alan Hisse Senetlerinin Kümelenmesi: COVID-19 Öncesi ve COVID-19 Dönemi İncelemesi \\ (Clustering of Stocks Included in Borsa Istanbul 30 Index: A Pre-COVID-19 and COVID-19 Period Analysis)
}

\author{
Turan KOCABIYIK (D) a Meltem KARAATLI (D) ${ }^{b}$ Kemal Berkay AKTAŞ ${ }^{\text {iD }}$ b \\ a Süleyman Demirel Üniversitesi, Finans ve Bankacılık Bölümü, Isparta, Türkiye. turankocabiyik@sdu.edu.tr \\ b Süleyman Demirel Üniversitesi, İşletme Bölümü, Isparta, Türkiye. meltemkaraatli@sdu.edu.tr \\ c Süleyman Demirel Üniversitesi, Sosyal Bilimler Enstitüsü, Isparta, Türkiye. berkayaktas@gmail.com
}

\begin{tabular}{l} 
MAKALE BİLGİsi \\
\hline Anahtar Kelimeler: \\
BIST 30 \\
Borsa İstanbul \\
Canopy Algoritması \\
Kümeleme \\
\\
Gönderilme Tarihi 25 \\
Haziran 2021 \\
Revizyon Tarihi 18 \\
Ağustos 2021 \\
Kabul Tarihi 30 Ağustos \\
2021
\end{tabular}

ÖZET

Amaç - Bu çalışma, Borsa İstanbul 30 (BIST 30) endeksine dahil hisse senetlerinin uzun yıllar boyunca gösterdikleri fiyat davranışlarına dayanmaktadır. Araştırmada kullanılan değişkenler yardımı ile Borsa İstanbul 30 endeksinde yer alan hisse senetlerinin Canopy Kümeleme Algoritması ile hangi kümede yer aldığını tespit etmek amaçlanmıştır.

Yöntem - Çalışmada, Canopy Algoritması ile kümeleme işlemi yapılmış sonrasında Wilcoxon ve Paired Sample t testi ile değişkenler bazında anlamlı farklılığın olup olmadığı incelenmiştir. Çalışmada kullanılan değişkenler, literatür taramaları ve uzman görüşleri dikkate alınarak belirlenmiştir. Çalışmaya dahil edilen hisse senetleri, 07.12.2020 tarihi itibarıla BIST 30 endeksinde yer alan hisse senetlerinden oluşmaktadır. Çalışmada kullanılan veri seti 2012-2020 dönemini kapsamakta ve her hisse senedinin günlük olarak; kapanış, beta katsayısı, volatilite, hacim, piyasa değeri/defter değeri (PD/DD) değişkenlerinden oluşmaktadır. Bu kapsamda veri seti COVID-19 pandemisi öncesi ve COVID-19 dönemi şeklinde iki grup halinde analize dahil edilmiştir.

Bulgular - Canopy Algoritmasının, kümeleme analizinde anlamlı sonuçlar ortaya koyduğu ve kümeleme sonuçları incelendiğinde 30 hisse senedinden 19 tanesinin hem pandemi öncesi hem de pandemi sonrası aynı kümede yer aldığı görülmüştür. Kümelerin oluşumunda değişkenlerin etkileri incelenmiş ve değişkenlerin kümeleme analizi için doğru seçimler olduğu sonucuna varılmıştır.

Makale Kategorisi: Araştırma Makalesi

Tartışma - Yatırım araçları, farklı risk getiri ilişkisine sahiptir. Hisse senetlerine yatırım yapmak isteyen yatırımcılar portföy çeşitlendirmesi yaparken hisse senetlerinin gösterecekleri davranışlara ilişkin bilgi sahibi olmalıdır. Yani düşüşlerde ve yükselişlerde birlikte hareket eden hisse senetlerine aynı portföyde yer vermenin portföyün toplam riskini azaltması açısından faydalı olacağı düşünülmemektedir. Bu noktada hisse senetlerini tanımak yatırımcılara çeşitli yararlar sağlayacaktır. Çalışma sonucunda ortaya çıkan verilerin, yatırımcılara hisse senedi seçimi konusunda karar verme sürecinde fayda sağlayacağı düşünülmektedir.

\begin{tabular}{l} 
ARTICLE INFO \\
\hline Keywords: \\
BIST 30 \\
Borsa Istanbul \\
Canopy Algorithm \\
Clustering
\end{tabular}

\section{ABSTRACT}

Purpose - This study is based on the price behavior of stocks included in the Borsa Istanbul 30 (BIST 30) index over many years. With the help of the variables used in the research, it is aimed to determine in which cluster the stocks in the Borsa Istanbul 30 index are included with the Canopy Clustering Algorithm.

Design/Methodology/Approach - In this study, clustering was performed with the Canopy Algorithm, and then it was examined whether there was a significant difference on the basis of variables with the Wilcoxon and Paired Sample $t$ test. The stocks included in the study consist of stocks included in the BIST 30 index as of 07.12.2020. The data set used in the study covers the period of 2012-2020 and each stock's daily; closing, beta coefficient, volatility, volume, market value/book value (PD/DD) variables. In this context, the data set was included in the analysis in two groups, pre-COVID-19 pandemic and COVID-19 period.

Received 25 June 2021

Revised 18 August 2021

Accepted 30 August 2021

Article Classification: Research Article
Findings - It was seen that the Canopy Algorithm revealed significant results in the clustering analysis and when the clustering results were examined, 19 of the 30 stocks were in the same cluster both before and after the pandemic. The effects of variables on the formation of clusters were examined and it was concluded that the variables were the right choices for cluster analysis.

Discussion - Investment instruments have different risk-return relationships. Investors who want to invest in stocks should have information about the behavior of stocks while diversifying their portfolio. In other words, it is not thought that it would be beneficial to include stocks that move together in decreases and increases in the same portfolio in terms of reducing the total risk of the portfolio. At this point, getting to know the stocks will provide various benefits to the investors.

\section{Önerilen Atıf/Suggested Citation}

Kocabıyık, T., Karaatlı, M., Aktaş, K.B. (2021). Borsa İstanbul 30 Endeksinde Yer Alan Hisse Senetlerinin Kümelenmesi: COVID-19 Öncesi ve COVID-19 Dönemi İncelemesi, İşletme Araştırmaları Dergisi, 13 (3), 2537-2551. 


\section{GİRISS}

İşletmelerin varlıklarını finanse etmede kullanabileceği iki grup kaynak bulunmaktadır. Bunlar borçlar ve öz kaynaklardır. Öz kaynakların en önemli bölümünü ise şirket ortaklarının şirkete aktardıkları sermaye oluşturur. Menkul kıymet borsaları şirketlerin hisse senedi ihracı yoluyla sermaye sağlamalarına imkân verir. Bu sağlanan fonlar da işletmelerin büyümelerine yardımcı olur. İşletmelerin büyümeleri beraberinde istihdam olanaklarının artmasını ve ülke ekonomisinin büyümesini de getirir. Ayrıca organize bir piyasa olarak borsalar şirketlerin belli bir biçimde hareket etmesini şart koşar. Ekonomik sonuç doğurabilecek olaylar, ortaklar genel kurul toplantılarına ilişkin gelişmeler, bilanço ve gelir tabloları kamuoyu ile düzenli olarak paylaşılır. Bu durum şirketlerin kurumsallaşmasına katkı sağlar. Yatırımcılar açısından değerlendirildiğinde ise borsalar kar potansiyeli yüksek şirketlere küçük tasarruflarla güven içinde ortak olmayı sağlar.

Borsa İstanbul' daki yabancı takası yaklaşık \%50 seviyelerindedir. Bu durum Borsa İstanbul'un uluslararası bir yatırım platformu olduğunu göstermektedir. Yabancı yatırımcılar Borsa İstanbul'da yatırım yapabilmek için ülkeye döviz girdisi de sağlamaktadır. Dolayısıyla Türkiye gibi cari açığını kapatmada doğrudan yabancı yatırımlarını önemseyen bir ülke için borsa önemli bir platformdur.

Yatırım araçlarının risk durumu değerlendirildiğinde hisse senetleri en riskli bölgede yer alan araçlardan biridir. Bu nedenle hisse senedi piyasalarına yapılacak yatırımlarda rasyonel davranılmalı ve çok dikkat edilmelidir. Aksi halde telafisi çok zor olan durumlarla karşılaşılması mümkün olmaktadır. Yatırımcıların doğru kararlar verebilmesi piyasa ile ilgili bilgiye yeterince sahip olması ile doğrudan ilgilidir.

$\mathrm{Bu}$ araştırma yatırımcıların hisse senedi piyasaları ile ilgili daha fazla bilgiye sahip olabilmesi için yapılmıştır. Borsa İstanbul 30 endeksinde yer alan hisse senetlerinin Canopy algoritması ile kümelenmesine dayanan bu çalışmanın sonuçları iki açıdan yatırımclara katkı sağlayacaktır. Bunlardan birincisi portföy çeşitlendirmesi ile ilgilidir. Çeşitlendirmede amaç portföyün toplam riskini düşürmektir. Araştırma sonuçlarına göre aynı kümede yer alan hisse senetleri belirlenen kriterler açısından benzer özellikler göstermektedir. Kapanış fiyatı, beta katsayısı, volatilite, hacim ve piyasa değeri/defter değeri (PD/DD) değişkenleri dikkate alındığında aynı kümede yer alan hisse senetlerinin portföy çeşitlendirmesinde kullanılmaması uygun olacaktır. Diğer taraftan aynı kümede yer almayanlar ise çeşitlendirmede kullanılabilir. İkinci katkıya gelince; aynı kümede yer alan bir hisse senedi aşağı yönlü ya da yukarı yönlü bir harekete başlamışsa kümenin diğer elemanları yatırımcılara kazanç fırsatları sağlayabilir. Örneğin, aynı kümede yer alan hisselerden biri belirgin bir biçimde yukarı yönlü harekete başlamışsa, henüz fiyat hareketine başlamamış diğer hisse senetlerinde uzun pozisyon alınarak kazanç sağlama imkânı elde edilebilir.

Çalışmada, Borsa İstanbul 30 endeksinde yer alan hisse senetlerine Canopy algoritması kullanılarak kümeleme işlemi yapılmış ve hisse senetleri gösterdikleri benzerliklere göre kümelere ayrılıp gösterilmiştir. Ayrıca kullanılan değişkenler arasında anlamlı bir farklılık olup olmadığı Wilcoxon ve Paired Sample $t$ testi ile incelenerek yorumlanmıştır. Kullanılan yöntem, değişkenler ve elde edilen sonuçlar, gelecekte yapılacak olan çalışmalara yol gösterici nitelikte olacağı düşünülmekte ve bulguların literatüre katkı sağlaması amaçlanmıştır.

\section{KAVRAMSAL ÇERÇEVE}

Bu bölümde öncelikle literatürde finans alanında yapılan kümeleme çalışmalarına yer verilmiş ardında da diğer alanlarda gerçekleştirilen çalışmalar açıklanmıştır.

Tablo 1. Finans Alanında Yapılmış Bazı Kümeleme Çalışmaları

\begin{tabular}{|c|c|c|c|}
\hline Yazar & Kullanılan Değişken & Metodoloji & Temel Bulgular \\
\hline (Şchiopu, 2010: 66-75) & $\begin{array}{c}\text { Kredi geçmişi, kredi } \\
\text { tutarı, çalışma süresi, } \\
\text { ödeme oranı, medeni } \\
\text { hal }\end{array}$ & $\begin{array}{c}\text { İki Adımlı } \\
\text { Kümeleme Metodu }\end{array}$ & $\begin{array}{l}\text { Analiz sonucunda üç müşteri } \\
\text { profili belirlenmiştir. En } \\
\text { önemli profil, amacı eğitim } \\
\text { veya iş için kredi almak olan } \\
\text { kötü kredi geçmişi olmayan } \\
\text { nitelikli müşterileri içerir. } \\
\text { İkinci profil, işsiz, ancak } \\
\text { gayrimenkullü ve kredisi }\end{array}$ \\
\hline
\end{tabular}


T. Kocabıyık - M. Karaatlı - K. B. Aktaş 13/3 (2021) 2537-2551

\begin{tabular}{|c|c|c|c|}
\hline & & & $\begin{array}{l}\text { yeniden eğitim veya ev } \\
\text { eşyaları için olan orta sınıf } \\
\text { müşterileri gruplandırır. } \\
\text { Üçüncü profil, bilinmeyen } \\
\text { mülkleri olan, çoğunlukla } \\
\text { işsiz olan ve bir şeyler için } \\
\text { kredi almak isteyen kişileri } \\
\text { gruplandırır. }\end{array}$ \\
\hline $\begin{array}{c}\text { (Karaatlı vd., 2019: 871- } \\
\text { 886) }\end{array}$ & $\begin{array}{l}\text { Hisse senetlerinin } \\
\text { günlük olarak artış, } \\
\text { azalış ve sabit kalma } \\
\text { durumları }\end{array}$ & $\begin{array}{c}\text { Beklenti } \\
\text { Maksimizasyonu } \\
\text { Algoritması }\end{array}$ & $\begin{array}{l}\text { Aynı sektörde yer alan } \\
\text { işletmelerin, farklı } \\
\text { kümelerdeki dağılımlarından } \\
\text { yola çıkılarak artış, azalış ve } \\
\text { sabit kalma zamanlarında } \\
\text { işletmelerin sektör olarak } \\
\text { birlikte hareket etmediği } \\
\text { sonucuna varılmıstır. }\end{array}$ \\
\hline $\begin{array}{c}\text { (Yilmaz vd., 2020: 1753- } \\
\text { 1773) }\end{array}$ & $\begin{array}{l}\text { Kripto para birimleri } \\
\text { adres sayıları, piyasa } \\
\text { değerleri, fiyatlar, } \\
\text { iadeler, arz miktarı, } \\
\text { işlem sayısı, işlem } \\
\text { hacmi ve volatilite }\end{array}$ & $\begin{array}{l}\text { Ward, Tam Bağlantı } \\
\text { ve Tek Bağlantı } \\
\text { teknikleri }\end{array}$ & $\begin{array}{l}\text { Kümeleme sonucunda } 3 \\
\text { farklı küme oluşmuş ve } \\
\text { analizde yer alan tüm kripto } \\
\text { paralar ele alınan üç farklı } \\
\text { dönemde de aynı kümede yer } \\
\text { almıştır. }\end{array}$ \\
\hline (Aydın, 2013: 29-47) & $\begin{array}{l}\text { Sermaye yeterlilik } \\
\text { rasyoları, çok boyutlu } \\
\text { ölçekleme yöntemi }\end{array}$ & Ward tekniği & $\begin{array}{l}44 \text { adet banka } 7 \text { kümeye } \\
\text { ayrılarak sınıflandırılmıştır. } \\
\text { Çok boyutlu ölçekleme } \\
\text { analizinde ortaya çıan } \\
\text { benzer yapidaki bankalar } \\
\text { kümeleme analizinde de aynı } \\
\text { küme içerisinde yer almıştır. }\end{array}$ \\
\hline (Doğan, 2008) & $\begin{array}{l}\text { Finansal performans } \\
\text { gösterge oran seti, } \\
\text { bankaların aktif } \\
\text { büyüklükleri }\end{array}$ & $\begin{array}{l}\text { Tek Bağlantı, Tam } \\
\text { Bağlantı, Ortalama, } \\
\text { Merkezi ve Ward } \\
\text { kümeleme teknikleri }\end{array}$ & $\begin{array}{l}\text { Kümeleme analizinin, } \\
\text { finansal açıdan birbiriyle } \\
\text { benzerlik gösteren bankaları } \\
\text { tespit etmekte bir finansal } \\
\text { analiz ve uzaktan inceleme } \\
\text { aracı olarak kullanılabileceği } \\
\text { sonucuna varılmıştır }\end{array}$ \\
\hline $\begin{array}{c}\text { (Okumuş vd., 2010: 89- } \\
\text { 111) }\end{array}$ & $\begin{array}{l}\text { Sosyo-ekonomik ve } \\
\text { demografik özellikler }\end{array}$ & $\begin{array}{l}\text { Hiyerarşik olmayan } \\
\text { kümeleme analizi, } \\
\text { Ki-kare testi }\end{array}$ & 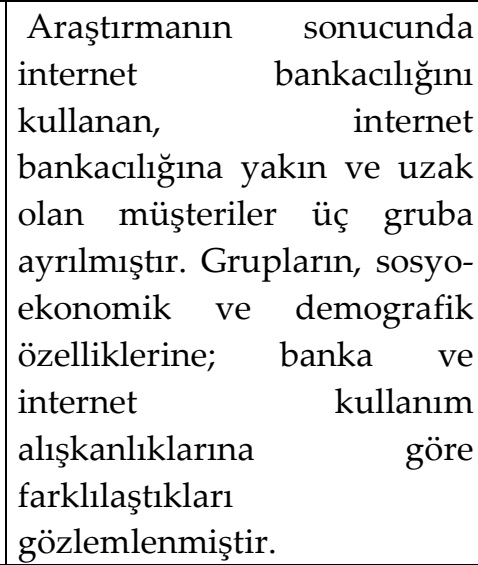 \\
\hline (Baynal vd., 2016: 13-41) & $\begin{array}{l}\text { Cinsiyet, medeni hal, } \\
\text { yaş, aylık gelir, eş } \\
\text { geliri, sahip olduğu ev, } \\
\text { araç, çocuk durumu, } \\
\text { maaş müşterisi olup }\end{array}$ & $\begin{array}{l}\text { K-ortalamalar } \\
\text { yöntemi }\end{array}$ & $\begin{array}{l}\text { Analiz sonucunda üç farklı } \\
\text { küme elde edilmiş ve bu } \\
\text { kümelerin içerdiği müşteri } \\
\text { portföyüne göre çeşitli } \\
\text { öneriler sunulmuştur. }\end{array}$ \\
\hline
\end{tabular}




\begin{tabular}{|c|c|c|c|}
\hline & $\begin{array}{l}\text { olmadığı, çalışma } \\
\text { şekli, öğrenim } \\
\text { durumu ve geri } \\
\text { ödeme durumu }\end{array}$ & & \\
\hline (Gazel vd., 2018: 147-164) & Geçmiş fiyat verileri & $\begin{array}{l}\text { Hiyerarşik Yığınsal } \\
\text { Kümeleme analizi, } \\
\text { Ward tekniği }\end{array}$ & $\begin{array}{l}\text { İncelenen hisse senetlerinin } \\
\text { bir kısmının BIST100'de ki } \\
\text { sektörel dağılıma benzer bir } \\
\text { kısmının ise aykırı şekilde } \\
\text { kümelendiği görülmüştür. }\end{array}$ \\
\hline $\begin{array}{c}\text { (Salighehdar vd., 2017: 1- } \\
\text { 8) }\end{array}$ & $\begin{array}{l}\text { Ticaret ve teklif verme } \\
\text { aktiviteleri }\end{array}$ & $\begin{array}{c}\text { Hiyerarşik } \\
\text { Kümeleme analizi, } \\
\text { Pearson korelasyon } \\
\text { katsayısı }\end{array}$ & $\begin{array}{l}\text { Hiyerarşik kümelemeden } \\
\text { elde edilen dendrogramların } \\
\text { yapısında bir tutarlılık } \\
\text { olduğu sonucuna varılmış ve } \\
\text { likidite önlemleri için öneriler } \\
\text { sunulmuştur. }\end{array}$ \\
\hline
\end{tabular}

Tablo 2. Diğer Alanlarda Yapılmış Bazı Kümeleme Çalışmaları

\begin{tabular}{|c|c|c|c|}
\hline Yazar & Kullanılan Değişken & Metodoloji & Temel Bulgular \\
\hline $\begin{array}{l}\text { (Ramoni vd., 2002: 9121- } \\
\text { 9126) }\end{array}$ & $\begin{array}{l}\text { Gen ekspresyonu } \\
\text { zaman serisi, insan } \\
\text { fibroblastları }\end{array}$ & $\begin{array}{l}\text { Bayes çıkarımı, gen } \\
\text { ekspresyon } \\
\text { dinamikleri }\end{array}$ & $\begin{array}{l}\text { Kümeleme işlemi, durağan } \\
\text { olmayan zaman serilerinin } \\
\text { varlığından büyük ölçüde } \\
\text { etkilenmediği sonucuna } \\
\text { varılmıştır. }\end{array}$ \\
\hline $\begin{array}{c}\text { (Clatworthy vd., 2005: 329- } \\
358)\end{array}$ & $\begin{array}{l}\text { Kümeleme } \\
\text { analizlerinin } \\
\text { raporlanması için } \\
\text { kullanılan kriterler }\end{array}$ & $\begin{array}{c}18 \text { sağlık psikolojisi } \\
\text { dergisinin 1984-2002 } \\
\text { yılları arasında } \\
\text { yayınlanan } \\
\text { makaleleri içinde } \\
\text { kümeleme analizi } \\
\text { raporları }\end{array}$ & $\begin{array}{l}\text { Birçok çalışmanın kalitesiz } \\
\text { olduğu, sağlık psikolojisinde } \\
\text { kümer analizlerinin } \\
\text { yürütülmesi ve raporlanması } \\
\text { için açı kılavuzlara ihtiyaç } \\
\text { olduğu sonucu çımıştır. }\end{array}$ \\
\hline (Punj vd., 1983: 134-148) & $\begin{array}{c}\text { Alternatif } \\
\text { küme analizi } \\
\text { yöntemleri, } \\
\text { performans özellikleri } \\
\text { ile ilgili yapılan son } \\
\text { çalışmalar }\end{array}$ & $\begin{array}{l}\text { Minimum varyans } \\
\text { yöntemi, basit } \\
\text { ortalama bağlantı } \\
\text { yoluyla ön } \\
\text { tanımlanması ve } \\
\text { yinelemeli bir } \\
\text { bölümleme } \\
\text { prosedürü ile küme } \\
\text { arıtma }\end{array}$ & $\begin{array}{l}\text { Kümeleme yöntemlerinde ilk } \\
\text { seçilen değişkenlerin çok } \\
\text { önemli olduğu vurgulanmış } \\
\text { ve pazarlamada kümeleme } \\
\text { analizinin daha çok } \\
\text { kullanılması önerilmiştir. }\end{array}$ \\
\hline $\begin{array}{c}\text { (Aldenderfer vd., 1988: } \\
\text { 447-473) }\end{array}$ & $\begin{array}{l}\text { Kümeleme analizinde } \\
\text { kullanılan metotlar }\end{array}$ & $\begin{array}{c}\text { Analizlerde } \\
\text { karşılaşılan sorunlar }\end{array}$ & $\begin{array}{l}\text { Kümeleme analizleri } \\
\text { derinlemesine incelenmiş ve } \\
\text { yaşanan problemler için } \\
\text { önerilerde bulunulmuştur. }\end{array}$ \\
\hline (Romesburg, 2004) & $\begin{array}{l}\text { Kümeleme analizinde } \\
\text { kullanılan teknikler }\end{array}$ & $\begin{array}{c}\text { Kümeleme analizi } \\
\text { hakkında yol } \\
\text { gösterici detaylı } \\
\text { bilgiler }\end{array}$ & $\begin{array}{l}\text { Araştırmacılar için } \\
\text { kümeleme analizi hakkında } \\
\text { detaylı bilgiler verilmiştir. }\end{array}$ \\
\hline (Eren vd., 2019: 421-452) & $\begin{array}{l}\text { Türkiye'de yer alan } 81 \\
\text { il ve illerdeki } 22 \text { sağlık } \\
\text { değişkeni }\end{array}$ & $\begin{array}{c}\text { Beklenti } \\
\text { Maksimizasyonu, } \\
\text { MULTIMOORA } \\
\text { yöntemi }\end{array}$ & $\begin{array}{lrr}\begin{array}{l}\text { Kümeleme ve } \\
\text { sonucunda, } \\
\text { gelişmişlik }\end{array} & \begin{array}{r}\text { sıralama } \\
\text { bölgesel } \\
\text { alanındaki }\end{array} \\
\text { farklılıkların } & \text { sağllk açısından }\end{array}$ \\
\hline
\end{tabular}




\begin{tabular}{|c|c|c|c|}
\hline & & & $\begin{array}{l}\text { da önemli bir farklılık } \\
\text { gösterdiği gözlemlenmiştir. }\end{array}$ \\
\hline (Danac1 vd., 2017: 351-370) & $\begin{array}{l}\text { Dış ticaret hacmi, } \\
\text { istihdam, kuruluş } \\
\text { alanı ve faaliyet } \\
\text { gösteren işletme } \\
\text { sayıları }\end{array}$ & $\begin{array}{c}\text { Hiyerarşik } \\
\text { Kümeleme Analizi }\end{array}$ & $\begin{array}{l}\text { Kümeleme sonucunda } 4 \\
\text { küme ortaya çıkmış ve serbest } \\
\text { bölgeler arasında birbiriyle } \\
\text { benzerlik gösteren iller, } \\
\text { Gaziantep ve Denizli serbest } \\
\text { bölgeleri, en az benzerlik } \\
\text { gösteren iller, Ege ve Bursa } \\
\text { serbest bölgeleri olduğu } \\
\text { ortaya çıkmıştır. }\end{array}$ \\
\hline
\end{tabular}

\section{YÖNTEM}

Literatüre bakıldığında çok sayıda kümeleme algoritması bulunmaktadır. Bu çalışmada kümeleme analizi yapılırken WEKA programından faydalanılmış ve program içerisinde yer alan çeşitli algoritmalar ile analiz gerçekleştirilmiştir. Sonuçlar değerlendirildiğinde en anlamlı sonucu veren Canopy Algoritması olduğu görülmüştür. Bu bölümde Canopy Algoritmasından bahsedilmiştir.

Canopy Algoritması; Andrew McCallum, Kamal Nigam ve Lyle Ungar tarafından 2000 yılında geliştirilmiştir (Akpınar, 2017: 401). Canopy Algoritması, verileri kabaca örtüşen birkaç alt gruba bölmektedir (Rong, 2011). Her alt küme, kümelemeyi hızlandırmak için genellikle düşük maliyetli benzerlik ölçütleri kullanan bir küme görevi görür (Yu ve Zhang, 2014). Bu nedenle Canopy Algoritması, genellikle diğer kümeleme algoritmalarını uygulama işlemlerinden önce büyük veri gruplarının kolay ve hızlı bir şekilde kümelenmesi için kullanılır (Yuan ve Yang, 2019: 231).

Bu algoritma iki aşamadan oluşmaktadır. İlk aşamada veri dizileri basit uzaklık metrikleri kullanarak kabaca kümelenirken, ikinci aşamada k-means ya da farklı algoritmalar kullanılarak ilk aşamadan elde edilen kaba kümelerin iyileştirilmesi sağlanır. İlk aşamada elde edilen canopy'ler aynı noktanın birden fazla canopy'de yer almasından üst üste gelir ve kubbeye benzer. Bu sebepten canopy (kubbe) algoritması denilmektedir. Kümeleme sürecinde T1 > T2 olmak üzere iki uzaklık eşiği kullanılır. Her nesnenin çok boyutlu değişkenler uzayında bir nokta ile temsil edildiği veri dizisinden tesadüfi olarak seçilen bir nokta ve bu noktayı merkez kabul eden bir canopy oluşturur ve veri dizisinde yer alan tüm noktaların seçilen bu noktaya olan uzaklıkları hesaplanır. Veri dizisinde yer alan noktaların bu tesadüfi olarak belirlenen noktaya olan kaba uzaklıkları tanımlanan T2 değerinden küçükse, bu noktalar ilgili canopy'nin asil üyesi olur ve veri dizisinden silinir ve bu noktalar aşısından süreç biter. Ancak noktalar T2 değerinden büyük, T1 değerinden küçükse bu canopy'nin bir üyesi olarak kabul edilir. Bu noktalar açısından hala kendi canopy'lerini kurma olasılıkları devam etmesinden dolayı noktalar veri kümesinden silinmez ve süreçte kalmaya devam eder bu durum veri dizisi bitene kadar devam eder (Akpınar, 2017: 401-403).

\subsection{Araştırmanın Amacı ve Kapsamı}

Araştırma bir kümeleme çalışması olup, Canopy algoritması kullanılmıştır. BIST 30 endeksinde yer alan hisse senetlerinin Canopy Kümeleme Algoritması ile COVID-19 pandemisi öncesi dönemi ve COVID-19 pandemisi döneminde hangi kümede yer aldığını tespit etmektir. Çalışma sonucunda ortaya çıan verilerin, yatırımclara hisse senedi seçimi konusunda karar verme sürecinde fayda sağlayacağı düşünülmektedir.

\subsection{Veri Seti Hakkında Bilgi}

Araştırmaya başlanılan tarih itibarıyla Borsa İstanbul 30 endeksinde yer alan hisse senetleri Tablo 3'de sunulmuştur. Araştırmaya dahil edilen veriler 2012-2020 dönemini kapsamaktadır. Bu dönem pandemi öncesi dönem ve pandemi olarak ikiye ayrılmıştır. Pandemi öncesi dönem 2012-2019 yıllarını kapsamakta olup, belirlenen değişkenlerin ortalaması alınmıştır. Pandemi sonrası dönem 2020 yılını kapsamaktadır. Veriler Matriks Prime veri dağıtım platformu ve Halk Yatırım internet sayfası aracılı̆̆ıyla elde edilmiştir. Günlük kapanış verileridir. 
T. Kocabıyık - M. Karaatlı - K. B. Aktaş 13/3 (2021) 2537-2551

Tablo 3. Araştırmada Kullanılan Borsa İstanbul 30 Endeksinde Yer Alan Hisse Senetleri

\begin{tabular}{|c|c|}
\hline Hisse Senedi Kodu & Şirket Adı \\
\hline AKBNK & AKBANK T.A.Ş. \\
\hline ARCLK & ARÇELIK A.Ş. \\
\hline ASELS & ASELSAN ELEKTRONIK SANAYİ VE TİCARET A.Ş. \\
\hline BIMAS & BİM BİRLEŞİK MAĞAZALAR A.Ş. \\
\hline DOHOL & DOĞAN ŞİRKETLER GRUBU HOLDİNG A.Ş. \\
\hline EKGYO & EMLAK KONUT GAYRIMENKUL YATIRIM ORTAKLIĞI A.Ş. \\
\hline EREGL & EREĞLİ DEMİR VE ÇELIKK FABRIKALARI T.A.Ş. \\
\hline GARAN & TÜRKIYYE GARANTİ BANKASI A.Ş. \\
\hline GUBRF & GÜBRE FABRIKALARI T.A.Ş. \\
\hline HALKB & TÜRKİYE HALK BANKASI A.Ş. \\
\hline ISCTR & TÜRKİYE İŞ BANKASI A.Ş. \\
\hline KCHOL & KOÇ HOLDİNG A.Ş. \\
\hline KOZAA & KOZA ANADOLU METAL MADENCİLIK İŞLETMELERİ A.Ş. \\
\hline KOZAL & KOZA ALTIN İŞLETMELERİ A.Ş. \\
\hline KRDMD & KARDEMİR KARABÜK DEMİR ÇELIK SANAYİ VE TİCARET A.Ş. \\
\hline MGROS & MİGROS TİCARET A.Ş. \\
\hline OYAKC & OYAK ÇİMENTO FABRIKKALARI A.Ş. \\
\hline PETKM & PETKIMM PETROKIMMYA HOLDİNG A.Ş. \\
\hline PGSUS & PEGASUS HAVA TAŞIMACILIĞI A.Ş. \\
\hline SAHOL & HACI ÖMER SABANCI HOLDİNG A.Ş. \\
\hline SISE & TÜRKIYYE ŞISŞE VE CAM FABRIKKALARI A.Ş. \\
\hline TAVHL & TAV HAVALIMANLARI HOLDİNG A.Ş. \\
\hline TCELL & TURKCELL İLETIŞİM HİZMETLERİ A.Ş. \\
\hline THYAO & TÜRK HAVA YOLLARI A.O. \\
\hline TKFEN & TEKFEN HOLDİNG A.Ş. \\
\hline TSKB & TÜRKIYYE SINAİ KALKINMA BANKASI A.Ş. \\
\hline TTKOM & TÜRK TELEKOMÜNIKASYON A.Ş. \\
\hline TUPRS & TÜPRAŞ-TÜRKIYYE PETROL RAFİNERILERİ A.Ş. \\
\hline VAKBN & TÜRKIYYE VAKIFLAR BANKASI T.A.O. \\
\hline YKBNK & YAPI VE KREDİ BANKASI A.Ş. \\
\hline
\end{tabular}


Kümeleme yapılırken dikkate alınan değişkenler Tablo 4' de sunulmuştur.

Tablo 4. Araştırmaya Dahil Edilen Değişkenler

\begin{tabular}{|c|l|}
\hline Değişken Adı & Açıklama \\
\hline Kapanış & Hisse senedinin günlük kapanış verisidir. \\
\hline Beta & Hisse senedinin BIST100 endeksine göre hesaplanan beta değeridir. \\
\hline Volatilite & Şirket hisse senetlerinin fiyat oynaklığını göstermektedir. \\
\hline Hacim & İşlem hacmini yansıtmaktadır. \\
\hline PD/DD & Şirketler için piyasa değerleri/defter değerleri formülüyle hesaplanan değerdir. \\
\hline
\end{tabular}

Tablo 4'den de anlaşılacağı üzere hisse senedinin gün sonundaki kapanış fiyatı, beta değeri, volatilite hesaplaması, işlem hacmi ve piyasa değeri/defter değeri hesaplama sonucu alınmıştır. Beta değeri bir hisse senedinin hareketlilik katsayısıdır ve hisse senedi fiyatındaki yüzde endekste meydana gelen yüzde değişime bölünmesi ile bulunur. Volatilite fiyat oynaklık ölçüsüdür. İşlem hacmi hisse senedinin hangi yoğunlukta işlem gördügünü gösterirken piyasa değeri/ defter değeri ise şirketin hisse senedi fiyatına bağlı hesaplanan piyasa değeri ile muhasebe kayıtlarında oluşan değerin oranlanması ile bulunur. Bu değişkenlerin hiçbiri tek başına yatırım yapıp yapmama konusunda fikir veremeyebilir ama bu değişkenler yazılı ve görsel medya araçlarında yatırımcıların sıklıkla incelediği ve önemsediği değişkenlerdir. Ayrıca birlikte değerlendirildiklerinde kümeleme yapmak için kullanılabilecek önemli değişkenler olduğu düşünülmektedir.

\subsection{Verilerin Analizi}

Analiz aşamasında ilk olarak araştırmaya dahil edilen değişkenlerin düzenlenmiş veri seti sunulmuştur. Ardından çalışmada, hisse senetlerinin pandemi öncesi ve pandemi dönemi ayrı ayrı değerlendirilerek kümeleme analizi sonuçlarına yer verilmiştir. Ayrıca pandemi öncesi ve pandemi dönemi arasında değişkenler açısından farklılık olup olmadığına bakılmıştır. Her iki dönem için oluşturulan veri seti Tablo 5 ve Tablo 6'da görülmektedir.

Tablo 5. Pandemi Öncesi Dönem (2012-2019) Veri Seti

\begin{tabular}{|c|c|c|c|c|c|}
\hline Hisse Senedi & $\begin{array}{c}\text { Kapanıs } \\
\text { TL }\end{array}$ & Beta & Volatilite & $\begin{array}{c}\text { Hacim } \\
\text { TL }\end{array}$ & PD/DD \\
\hline AKBNK & 6,36 & 1,39 & 3,41 & 202.867 .137 & 1,18 \\
\hline ARCLK & 14,61 & 0,84 & 3,51 & 28.683 .802 & 2,08 \\
\hline ASELS & 6,03 & 0,77 & 7,43 & 134.217 .343 & 4,03 \\
\hline BIMAS & 26,00 & 0,56 & 3,73 & 46.158 .377 & 11,91 \\
\hline DOHOL & 0,77 & 0,74 & 6,37 & 22.218 .417 & 0,68 \\
\hline EKGYO & 2,11 & 1,04 & 3,34 & 95.808 .249 & 1,30 \\
\hline EREGL & 2,11 & 1,04 & 3,34 & 95.808 .249 & 1,30 \\
\hline GARAN & 3,85 & 0,84 & 4,29 & 91.134 .098 & 1,32 \\
\hline GUBRF & 4,28 & 0,85 & 5,82 & 15.003 .243 & 1,80 \\
\hline HALKB & 10,84 & 1,41 & 3,66 & 276.857 .471 & 1,84 \\
\hline ISCTR & 5,03 & 1,31 & 3,26 & 191.142 .724 & 0,84 \\
\hline KCHOL & 11,67 & 0,97 & 2,78 & 55.768 .285 & 1,40 \\
\hline KOZAA & 3,90 & 1,02 & 7,49 & 69.659 .606 & 0,94 \\
\hline KOZAL & 30,10 & 0,85 & 5,30 & 54.821 .258 & 2,60 \\
\hline KRDMD & 1,57 & 1,14 & 3,94 & 133.142 .449 & 1,08 \\
\hline MGROS & 19,37 & 0,93 & 5,18 & 18.824 .577 & 5,16 \\
\hline OYAKC & 2,87 & 0,46 & 9,07 & 1.735 .131 & 2,20 \\
\hline PETKM & 1,96 & 0,81 & 4,52 & 108.714 .514 & 2,05 \\
\hline PGSUS & 27,59 & 1,06 & 7,51 & 57.000 .121 & 1,89 \\
\hline
\end{tabular}


T. Kocabiyık - M. Karaatlı - K. B. Aktaş 13/3 (2021) 2537-2551

\begin{tabular}{|c|c|c|c|r|c|} 
SAHOL & 8,06 & 1,10 & 3,40 & 58.518 .557 & 0,94 \\
\hline SISE & 2,88 & 0,94 & 3,17 & 25.930 .373 & 1,31 \\
\hline TAVHL & 13,95 & 0,72 & 4,85 & 26.522 .403 & 2,64 \\
\hline TCELL & 9,33 & 0,72 & 3,42 & 85.958 .963 & 1,81 \\
\hline THYAO & 8,69 & 1,18 & 4,68 & 491.162 .570 & 1,00 \\
\hline TKFEN & 8,51 & 0,81 & 3,80 & 28.732 .746 & 1,34 \\
\hline TSKB & 0,89 & 0,94 & 3,82 & 11.736 .228 & 1,10 \\
\hline TTKOM & 5,56 & 0,82 & 3,78 & 50.365 .636 & 4,24 \\
\hline TUPRS & 60,97 & 0,75 & 3,81 & 96.140 .227 & 2,68 \\
\hline VAKBN & 4,58 & 1,48 & 3,35 & 158.929 .502 & 1,15 \\
\hline YKBNK & 2,53 & 1,31 & 3,26 & 110.760 .047 & 0,86 \\
\hline
\end{tabular}

Tablo 6. Pandemi Dönemi (2020) Veri Seti

\begin{tabular}{|c|c|c|c|c|c|}
\hline Hisse Senedi & $\begin{array}{c}\text { Kapanış } \\
\text { TL }\end{array}$ & Beta & Volatilite & $\begin{array}{c}\text { Hacim } \\
\text { TL }\end{array}$ & PD/DD \\
\hline AKBNK & 6,08 & 1,23 & 9,48 & 475.083 .309 & 0,57 \\
\hline ARCLK & 20,67 & 0,94 & 8,05 & 162.982 .505 & 1,35 \\
\hline ASELS & 15,22 & 1,15 & 15,50 & 889.444 .488 & 2,45 \\
\hline BIMAS & 60,95 & 0,51 & 15,60 & 212.314 .508 & 8,01 \\
\hline DOHOL & 2,04 & 0,90 & 7,19 & 158.895 .567 & 0,72 \\
\hline EKGYO & 1,69 & 1,26 & 10,00 & 626.556 .532 & 0,47 \\
\hline EREGL & 1,69 & 1,26 & 10,00 & 626.556 .532 & 0,47 \\
\hline GARAN & 8,83 & 0,74 & 9,96 & 262.597 .426 & 0,94 \\
\hline GUBRF & 24,26 & 1,00 & 22,93 & 156.017 .751 & 14,04 \\
\hline HALKB & 5,60 & 1,13 & 8,17 & 352.861 .192 & 0,40 \\
\hline ISCTR & 5,58 & 1,18 & 10,63 & 236.740 .287 & 0,42 \\
\hline KCHOL & 16,55 & 1,02 & 9,77 & 175.266 .544 & 1,10 \\
\hline KOZAA & 12,11 & 1,07 & 6,05 & 194.007.114 & 1,56 \\
\hline KOZAL & 76,38 & 0,71 & 4,44 & 166.790 .778 & 1,92 \\
\hline KRDMD & 2,97 & 1,25 & 13,29 & 756.255 .691 & 0,90 \\
\hline MGROS & 33,67 & 0,95 & 10,26 & 139.407 .451 & 60,09 \\
\hline OYAKC & 6,75 & 0,84 & 9,94 & 94.360 .221 & 3,97 \\
\hline PETKM & 3,32 & 1,05 & 9,67 & 749.245 .961 & 1,73 \\
\hline PGSUS & 53,23 & 1,33 & 9,44 & 302.682 .397 & 1,09 \\
\hline SAHOL & 8,69 & 0,99 & 9,54 & 115.339 .923 & 0,54 \\
\hline SISE & 5,60 & 1,03 & 10,87 & 688.027 .379 & 1,12 \\
\hline TAVHL & 18,68 & 1,00 & 8,56 & 133.190 .777 & 0,85 \\
\hline TCELL & 14,37 & 0,75 & 7,61 & 304.768 .983 & 1,73 \\
\hline THYAO & 11,52 & 1,24 & 10,57 & 1.174 .941 .552 & 0,39 \\
\hline TKFEN & 15,02 & 1,15 & 4,47 & 214.552 .967 & 1,05 \\
\hline TSKB & 1,29 & 1,15 & 18,57 & 307.978 .954 & 0,66 \\
\hline TTKOM & 7,32 & 1,23 & 9,27 & 168.953 .589 & 2,67 \\
\hline TUPRS & 89,99 & 0,92 & 7,85 & 487.625 .649 & 1,99 \\
\hline VAKBN & 4,84 & 1,33 & 10,88 & 350.213 .410 & 0,53 \\
\hline YKBNK & 2,35 & 1,14 & 13,04 & 442.157 .742 & 0,47 \\
\hline
\end{tabular}




\section{BULGULAR}

\subsection{Canopy Algoritması ile Kümeleme Analizi Sonuçları}

Canopy Algoritması ile kümeleme yapılırken küme sayısı, programın varsayılan değerinde bırakılıp değiştirilmeyebilir ya da çalışmacı tarafından belirlenebilir. Küme sayısı belirlenirken literatürde yer alan Eşitlik 1'den yararlanılabilir (Turanlı vd., 2006: 100).

$k=\sqrt{n / 2}$

Eşitlik 1'e göre $n$ kümelenecek birim sayısını, $\mathrm{k}$ ise küme sayısını göstermektedir. Bu çalışmada da eşitlikten faydalanılarak yapılmış hesaplama neticesinde küme sayısı 4 olarak belirlenmiştir.

Tablo 5 ve Tablo 6'da yer alan 2012-2019 ve 2020 dönemlerine ait veriler, 2 farklı şekilde WEKA programı içerisinde yer alan Canopy Algoritması ile kümelenmiştir. WEKA programı sonuç ekranı Şekil 1 ve Şekil 2'de gösterilmiştir.

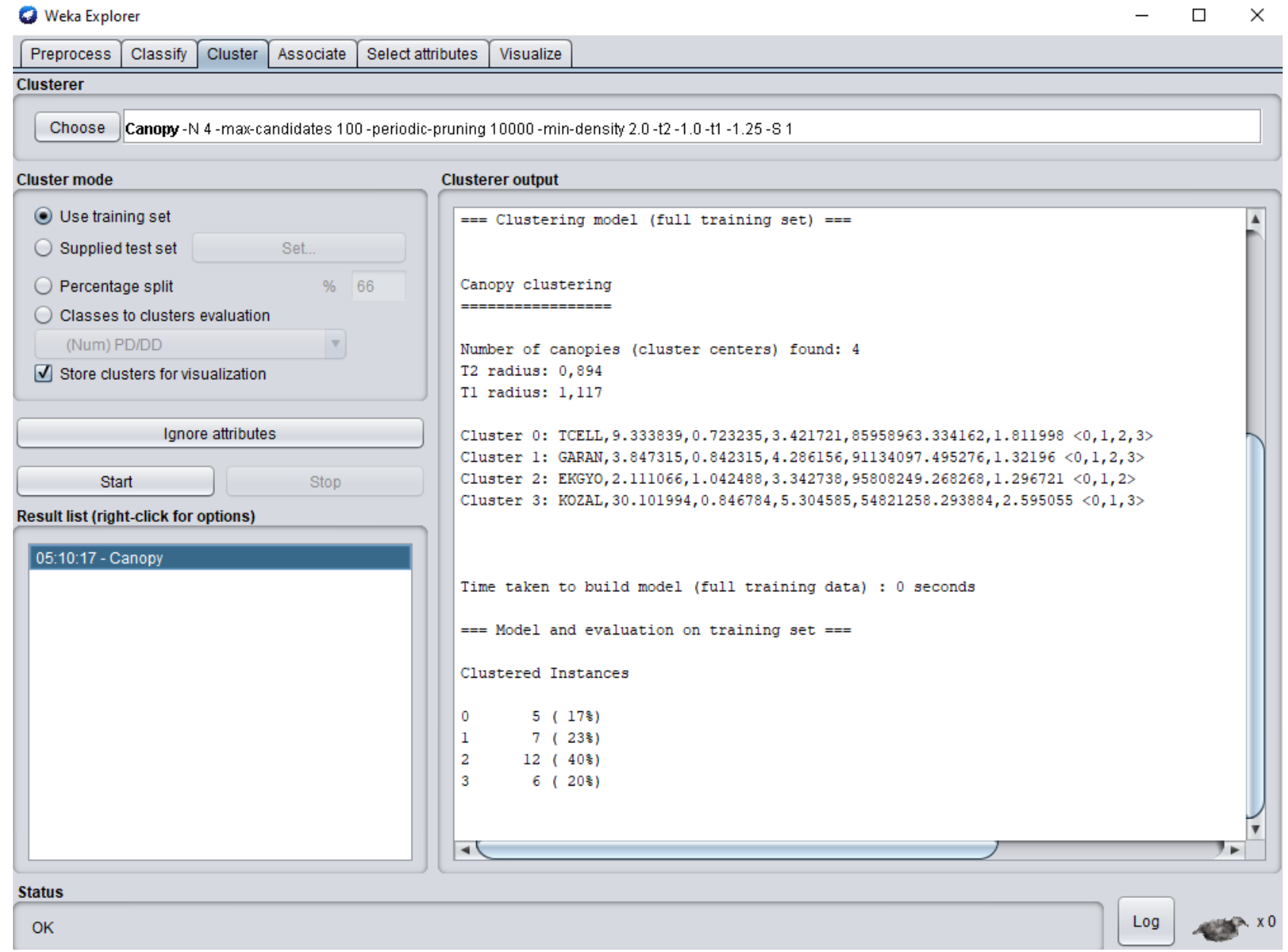

Şekil 1. Canopy Algoritması 2012-2019 Yılı Kümeleme Sonuç Ekranı

Şekil 1'de görüleceği üzere 2012-2019 döneminin yer aldığı veri seti kümelenmiş ve kümeleme sonucunda ilk kümede 5, ikinci kümede 7, üçüncü kümede 12 ve son kümede 6 hisse senedi yer almaktadır. 
Weka Explorer

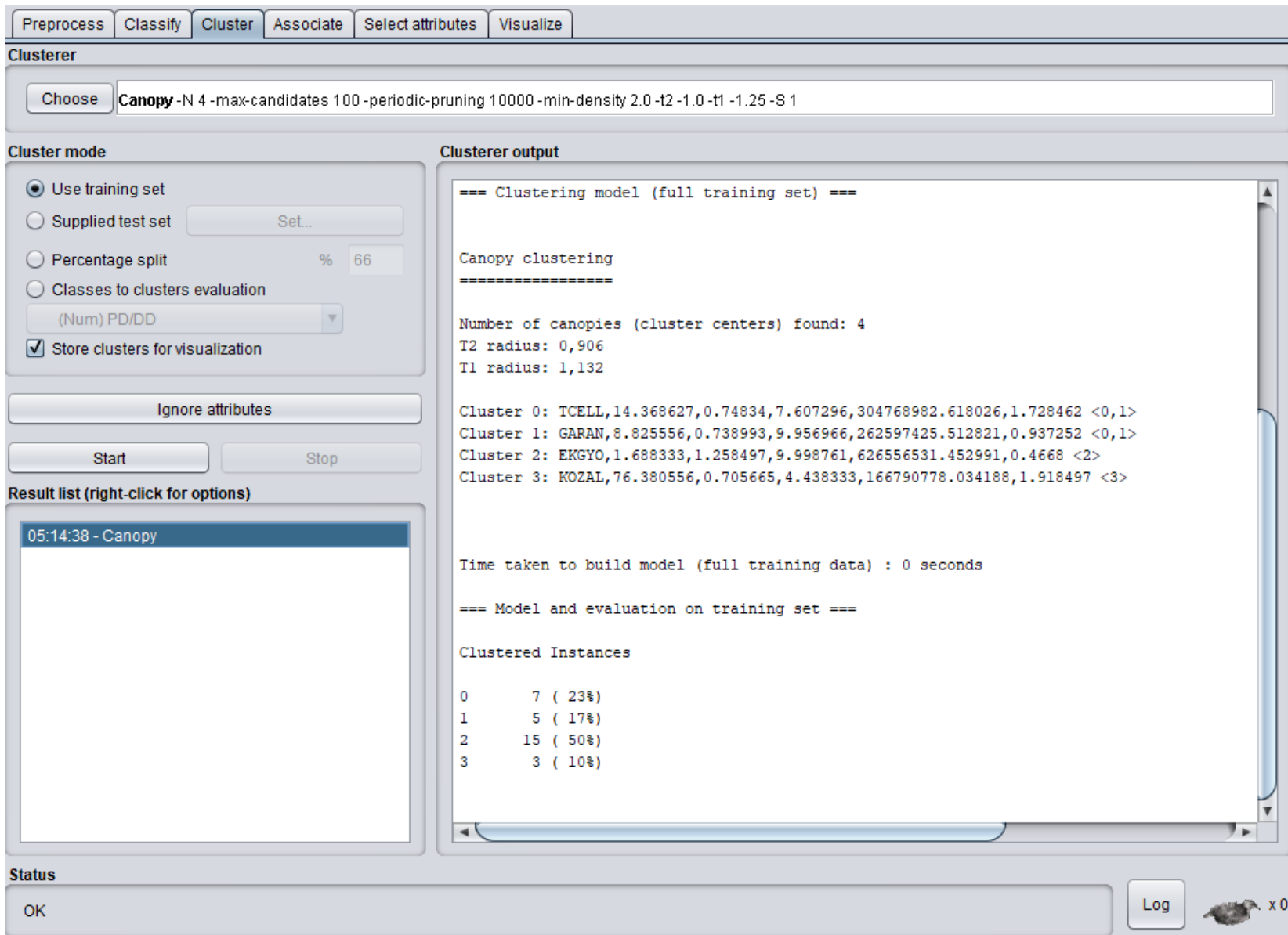

Şekil 2. Canopy Algoritması 2020 Yılı Kümeleme Sonuç Ekranı

Şekil 2 incelendiğinde COVID-19 pandemi döneminin (2020) yer aldığı veri seti kümelenmiş ve sonuç olarak; ilk kümede 7, ikinci kümede 5, üçüncü kümede 15 ve son kümede 3 hisse senedi yer almaktadır. Canopy Algoritması ile yapılan kümeleme analizi sonucunda elde edilen kümeler Tablo 7'de sunulmuştur.

Tablo 7. Canopy Algoritması Kümeleme Sonuçları

\begin{tabular}{|l|l|l|l|l|l|l|l|}
\hline \multicolumn{9}{|c|}{ 2012-2019 } & \multicolumn{5}{c|}{ 2020 } \\
\hline Küme 1 & Küme 2 & Küme 3 & Küme 4 & Küme 1 & Küme 2 & Küme 3 & Küme 4 \\
\hline ARCLK & ASELS & AKBNK & BIMAS & ARCLK & GARAN & AKBNK & BIMAS \\
\hline TAVHL & DOHOL & EKGYO & KOZAL & DOHOL & GUBRF & ASELS & KOZAL \\
\hline TCELL & GARAN & EREGL & MGROS & KOZAA & KCHOL & EKGYO & TUPRS \\
\hline TKFEN & GUBRF & HALKB & OYAKC & MGROS & OYAKC & EREGL & \\
\hline TTKOM & KOZAA & ISCTR & PGSUS & TAVHL & SAHOL & HALKB & \\
\hline & PETKM & KCHOL & TUPRS & TCELL & & ISCTR & \\
\hline & TSKB & KRDMD & & TKFEN & & KRDMD & \\
\hline & & SAHOL & & & & PETKM & \\
\hline & & SISE & & & & PGSUS & \\
\hline & & THYAO & & & & SISE & \\
\hline & & VAKBN & & & & THYAO & \\
\hline & & YKBNK & & & & TSKB & \\
\hline & & & & & & TTKOM & \\
\hline & & & & & & VAKBN & \\
\hline & & & & & & YKBNK & \\
\hline
\end{tabular}


Pandemi öncesi dönem yani 2012-2019 yılları arasını kapsayan dönemde 4 küme yer almaktadır. Bu kümeleri incelediğimizde Küme 1'de dayanıklı tüketim malları üreten Arçelik, hava limanı hizmetleri veren TAV Hava Limanları Holding, çok farklı alanlarda faaliyet gösteren Tekfen Holding ve iletişim teknolojileri alanlarında faaliyet gösteren Turkcell ve Türk Telekom yer almaktadır. Pandemi dönemi incelendiğinde bu kümeden 4 şirketin yine aynı kümede yer aldığı görülmektedir. Arçelik, TAV Havalimanları Holding, Turkcell ve Tekfen Holding her iki dönemde de aynı kümede yer almıştır.

2012-2019 döneminde Küme 2'de yer alan şirket sayısı 7'dir. Bu kümede yer alan şirketlerin sadece 2 tanesi pandemi döneminde Küme 2'de yer almıştır. Diğer şirketlerin pandemi döneminde diğer kümelere dağıldığı görülmektedir. Pandemi döneminde Türk iş dünyasının önde gelen iki önemli grubundan Koç Holding ve Sabancı Holding Küme 2' de birlikte yer almıştır.

Küme 3 her iki dönemde de en fazla hisse senedinin kümelendiği yer olmuştur. Pandemi öncesi dönemde kümede yer alan şirket sayısı 12' dir. Pandemi döneminde ise $15^{\prime}$ tir. Hem pandemi öncesinde hem pandemi döneminde bankaların önemli bir grubu bu kümelerde yer almıştır. Ayrıca demir-çelik sektörünün iki önemli şirketi de bankalara eşlik etmiştir. Ereğli Demir Çelik ve Karabük Demir Çelik şirketleri bankalarla birlikte bu kümede yer almıştır.

Algoritmanın belirlediği son kümeler incelendiğinde ise pandemi öncesi dönemden BİM AŞ, Koza Altın İşletmeleri ve TÜPRAŞ hisselerinin pandemi döneminde de birlikte kümelendiği göze çarpmaktadır. Pandemi öncesi dönemde kümede yer alan hisse senedi sayısı 6 iken pandemi döneminde 4 . Kümede yer alan hisse senedi sayısı 3'e inmiştir.

\section{2. İstatistiksel Analizler}

Bu bölümde 2012-2019 pandemi öncesi dönem ile 2020 pandemi dönemi arasında değişkenler açısından anlamlı bir farklılığın olup olmadığına bakılmıştır. İkinci olarak her iki dönemin kendi içinde değerlendirilmesi yapılarak kümeler arasında değişkenler bazında anlamlı farklılığın olup olmadığı incelenmiştir.

\subsubsection{2-2019 Pandemi Öncesi Dönem ile 2020 Pandemi Dönemi Arasında Değişkenler Açısından Anlamlı Bir Farklılığın Olup Olmadığının Tespit Edilmesi}

2012-2019 Pandemi Öncesi Dönem ile 2020 Pandemi Dönemi arasında belirlenen değişkenler arasında anlamlı farklılıkların olup olmadığına ilişkin değişkenin normal dağılıp dağılmadığı dikkate alınarak Wilcoxon Testi ve Paired Sample t Testi yapılmıştır. Tablo 8' de Kolmogorov-Smirnov Normallik Testi, Tablo 9' da da Wilcoxon Testi ve Paired Sample t Testi sonuçları yer almaktadır.

Tablo 8. Kolmogorov-Smirnov Normallik Testi

\begin{tabular}{|c|c|c|}
\hline \multirow{2}{*}{ Değişkenler } & $\mathbf{2 0 1 2 - 2 0 1 9}$ & $\mathbf{2 0 2 0}$ \\
\cline { 2 - 3 } & Sig. (p değeri) & Sig. (p değeri) \\
\hline Kapanış & .000 & .000 \\
\hline Beta & .156 & .200 \\
\hline Volatilite & .000 & .000 \\
\hline Hacim & .003 & .006 \\
\hline PD/DD & .000 & .000 \\
\hline
\end{tabular}

Test sonuçlarına göre beta değeri her iki dönem dikkate alındığında normal dağılırken, diğer değişkenler normal dağılım göstermemektedir. Bu sebepten dolayı değişkenlerin pandemi öncesi ve pandemi dönemi anlamlı farklılıklarının olup olmadığını kıyaslarken beta değişkeni için Paired Sample $t$ Testi, diğer değişkenlerin farklılıkları için Wilcoxon Testi yapılmıştır. Test sonuçları Tablo 9 ve Tablo 10'da verilmektedir. 
T. Kocabıyık - M. Karaatlı - K. B. Aktaş 13/3 (2021) 2537-2551

Tablo 9. Wilcoxon Testi

\begin{tabular}{|c|c|c|c|c|c|c|}
\hline & & $\mathrm{N}$ & Mean Rank & Sum of Ranks & $\mathrm{Z}$ & Sig. (p) \\
\hline skapanış - ökapanış & $\begin{array}{r}\text { Negative Ranks } \\
\text { Positive Ranks } \\
\text { Ties } \\
\text { Total } \\
\end{array}$ & $\begin{array}{c}5(\mathrm{a}) \\
25(\mathrm{~b}) \\
0(\mathrm{c}) \\
30 \\
\end{array}$ & $\begin{array}{c}7.00 \\
17.20\end{array}$ & $\begin{array}{c}35.00 \\
430.00\end{array}$ & $-4.062(\mathrm{a})$ & .000 \\
\hline svolatilite - övolatilite & $\begin{array}{r}\text { Negative Ranks } \\
\text { Positive Ranks } \\
\text { Ties } \\
\text { Total }\end{array}$ & $\begin{array}{l}2(\mathrm{~d}) \\
28(\mathrm{e}) \\
0(\mathrm{f}) \\
30\end{array}$ & $\begin{array}{c}4.00 \\
16.32\end{array}$ & $\begin{array}{c}8.00 \\
457.00\end{array}$ & $-4.618(a)$ & .000 \\
\hline shacim - öhacim & $\begin{array}{r}\text { Negative Ranks } \\
\text { Positive Ranks } \\
\text { Ties } \\
\text { Total }\end{array}$ & $\begin{array}{c}0(\mathrm{~g}) \\
30(\mathrm{~h}) \\
0(\mathrm{i}) \\
30\end{array}$ & $\begin{array}{c}.00 \\
15.50\end{array}$ & $\begin{array}{c}.00 \\
465.00\end{array}$ & $-4.782(a)$ & .000 \\
\hline sPP/DD - öPP/DD & $\begin{array}{r}\text { Negative Ranks } \\
\text { Positive Ranks } \\
\text { Ties } \\
\text { Total }\end{array}$ & $\begin{array}{c}25(\mathrm{j}) \\
5(\mathrm{k}) \\
0(\mathrm{l}) \\
30\end{array}$ & $\begin{array}{l}14.54 \\
20.30\end{array}$ & $\begin{array}{l}363.50 \\
101.50\end{array}$ & $-2.695(b)$ & .007 \\
\hline
\end{tabular}

a Based on negative ranks, b Based on positive ranks, c Wilcoxon Signed Ranks Test

*** Değişken isimlerinin başında bulunan s, pandemi dönemini ve ö, pandemi öncesi dönemi ifade etmektedir.

Tablo 9'da yer alan Wilcoxon Test sonuçlarına göre 2012-2019 pandemi öncesi ve 2020 pandemi dönemi arasında kapanış, volatilite, hacim ve PP/DD değişkenleri açısından istatistiksel olarak anlamlı bir farklılığın olduğu söylenebilir.

Tablo 10. Paired Sample t Testi

\begin{tabular}{|c|c|c|c|c|c|c|c|c|c|}
\hline & & & Paire & Differen & & & $\mathrm{t}$ & $\mathrm{df}$ & Sig. (2-tailed) \\
\hline & & Mean & $\begin{array}{c}\text { Std. } \\
\text { Deviation }\end{array}$ & $\begin{array}{l}\text { Std. } \\
\text { Error } \\
\text { Mean }\end{array}$ & $\begin{array}{r}95 \\
\text { Confi } \\
\text { Interva } \\
\text { Differ }\end{array}$ & $\begin{array}{l}\% \\
\text { dence } \\
1 \text { of the } \\
\text { rence }\end{array}$ & Mean & $\begin{array}{c}\text { Std. } \\
\text { Deviation }\end{array}$ & Std. Error Mean \\
\hline & & Lower & Upper & Lower & Upper & Lower & Upper & Lower & Upper \\
\hline $\begin{array}{l}\text { Pair } \\
1\end{array}$ & $\begin{array}{l}\text { öbeta } \\
\text { sbeta }\end{array}$ & -.08833 & .18771 & .03427 & -.15843 & -.01824 & -2.577 & 29 & .015 \\
\hline
\end{tabular}

*** Değişken isimlerinin başında bulunan s, pandemi dönemini ve ö, pandemi öncesi dönemi ifade etmektedir.

Tablo 10 dikkate alındığında, Paired Sample t Testi sonuçlarına göre 2012-2019 pandemi öncesi ve 2020 pandemi dönemi arasında beta değişkeni açısından istatistiksel olarak anlamlı bir farklılığın olduğu söylenebilir.

\subsubsection{2-2019 Pandemi Öncesi Dönem ile 2020 Pandemi Dönemi Arasında Değişkenler Açısından Kümeler Arasında Anlamlı Bir Farklıı̆ı̆ın Olup Olmadı̆̆ının Tespit Edilmesi}

2012-2019 pandemi öncesi dönem ve 2020 pandemi döneminde oluşan kümelerde kümeler arasında değişkenler açısından anlamlı farklılıkların olup olmadığının analizi için değişkenlerin normal dağılım gösterip göstermediğine göre ANOVA testi ve Kruskal Wallis testleri yapılmıştır. Her iki dönem içinde beta değişkeninin normal dağılım şartı sağlamış ancak varyansların homojenliği için yapılan Levene Testi 20122019 pandemi öncesi dönemde anlamlı çıkmadığı için bu değişken için de Kruskal Wallis Testi, 2020 Pandemi Döneminde beta değişkeninin Levene Testi sonucuna göre varyansların homojen olduğu tespit edilmiş ve ANOVA Testi yapılmıştır. 
T. Kocabiyık - M. Karaatlı - K. B. Aktaş 13/3 (2021) 2537-2551

Tablo 11. Kümeler Arası Farklılıklar

\begin{tabular}{|c|c|c|c|c|c|c|}
\hline & \multirow{3}{*}{ Değişkenler } & \multicolumn{3}{|c|}{$\begin{array}{l}\text { Normal Dağılım Koşulunu Sağlayan } \\
\text { Değişkenlerin Test Sonuçları }\end{array}$} & \multicolumn{2}{|c|}{$\begin{array}{c}\text { Normal Dağılım Koşulunu } \\
\text { Sağlamayan Değişkenlerin Test } \\
\text { Sonuçları } \\
\end{array}$} \\
\hline & & Anova Testi & Tukey Testi & Tukey Testi p & $\begin{array}{c}\text { Kruskal } \\
\text { Wallis }\end{array}$ & Mean Rank (ortalama \\
\hline & & & & & p değeri & \\
\hline \multirow{20}{*}{ 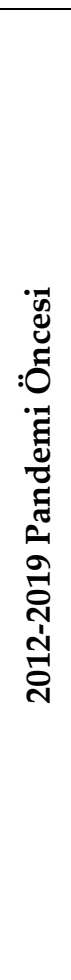 } & \multirow{4}{*}{ Kapanış } & \multirow{4}{*}{ - } & \multirow{4}{*}{ - } & \multirow{4}{*}{ - } & \multirow{4}{*}{.003} & Küme 1:20.80 \\
\hline & & & & & & Küme 2:8.00 \\
\hline & & & & & & Küme 3:13.08 \\
\hline & & & & & & Küme 4:24.67 \\
\hline & \multirow{4}{*}{ Volatilite } & \multirow{4}{*}{-} & \multirow{4}{*}{-} & \multirow{4}{*}{-} & \multirow{4}{*}{.000} & Küme 1:14.40 \\
\hline & & & & & & Küme 2: 23.14 \\
\hline & & & & & & Küme 3: 8.00 \\
\hline & & & & & & Küme 4: 22.50 \\
\hline & \multirow{4}{*}{ Hacim } & \multirow{4}{*}{-} & \multirow{4}{*}{ - } & \multirow{4}{*}{-} & \multirow{4}{*}{.017} & Küme 1:10.40 \\
\hline & & & & & & Küme 2:13.00 \\
\hline & & & & & & Küme 3:21.67 \\
\hline & & & & & & Küme 4:10.33 \\
\hline & \multirow{4}{*}{$\mathrm{PD} / \mathrm{DD}$} & \multirow{4}{*}{-} & \multirow{4}{*}{-} & \multirow{4}{*}{-} & \multirow{4}{*}{.001} & Küme 1:21.60 \\
\hline & & & & & & Küme 2:13.21 \\
\hline & & & & & & Küme 3:9.38 \\
\hline & & & & & & Küme 4:25.33 \\
\hline & & & & & & Küme 1: 7.40 \\
\hline & & & & & & Küme 2:11.57 \\
\hline & Beta & - & - & - & .000 & Küme 3:23.96 \\
\hline & & & & & & Küme 4:9.92 \\
\hline & & & & & & Küme 1:19.14 \\
\hline & & & & & 003 & Küme 2:18.20 \\
\hline & Kapanış & & & & .003 & Küme 3:10.20 \\
\hline & & & & & & Küme 3:29.00 \\
\hline & & & & & & Küme 1:7.14 \\
\hline & Volatilite & & & & 018 & Küme 2:18.20 \\
\hline & Volatilite & & & & .018 & Küme 3:19.27 \\
\hline$\stackrel{\bar{\Xi}}{\pi}$ & & & & & & Küme 4:11.67 \\
\hline : & & & & & & Küme 1:8.71 \\
\hline$\cdot \tilde{z}$ & Hacim & & & & 001 & Küme 2:6.60 \\
\hline שֶ & H & & & & & Küme 3:21.87 \\
\hline$\tilde{E}$ & & & & & & Küme 4:14.33 \\
\hline ิㅗㄱ & & & & & & Küme 1:18.36 \\
\hline & PD/DD & & & & 032 & Küme 2:19.00 \\
\hline & ID/DD & & & & .032 & Küme 3:11.10 \\
\hline & & & & & & Küme 4:25.00 \\
\hline & & & 1.Küme:3ve4 & .001-.021 & & \\
\hline & & & 2.Küme: 3 & .000 & & \\
\hline & Beta & .000 & 3.Küme:1,3,4 & .001-.000-.000 & - & - \\
\hline & & & 4.Küme:1,3 & $.021-.000$ & & \\
\hline
\end{tabular}

Tablo 11'e göre 2012-2019 döneminde kapanış, volatilite, hacim, PP/DD ve beta değişkenlerine göre kümeler arası dağılımlar farklılık göstermektedir. Kümelerin oluşmasında tüm değişkenlerin etkisinin olduğu görülmektedir. Bu da değişkenlerin kümeleme analizi için doğru seçimler olduğunu göstermektedir. 2020 
pandemi dönemi için de benzer bir durum geçerlidir. Çalışmada kullanılan değişkenler kümelerin farklı dağılmasında etkilidir.

\section{SONUÇ ve TARTIŞMA}

Sermaye piyasası araçlarının en önde gelenlerinden hisse senetleri hem dünyada hem de Türkiye'de geçmişten günümüze yatırımcıların ilgi gösterdiği temel araçlardandır. Hisse senetlerine yatırım somut olarak bir şirkete ortak olmak anlamına geldiği için birçok türev araçtan bu yönüyle ayrışır. Riskli yatırım araçları grubunda yer alır. Hisse senetlerine yatırım yapacaklar için temel soru hangi hisse senedine yatırım yapmalı ve ne miktarda yatırım yapılmalıdır. Bu çalışma birinci soruya cevap bulma noktasında yatırımcılara yardımcı olabilecek bir çalışmadır. Araştırma kapsamında Borsa İstanbul 30 endeksinde yer alan hisse senetlerinin kapanış, beta katsayısı, volatilite, hacim, piyasa değeri/defter değeri değişkenleri dikkate alınarak COVID-19 pandemisi öncesi (2012-2019) ve 2020 yılı itibarıyla pandemi döneminde kümelenmesi gerçekleştirilmiştir. Çalışmada kullanılan Canopy Algoritmasının, gerçekleştirilen kümeleme analizinde anlamlı bir kümeleme yaptığı görülmüştür. Elde edilen bulgularla hisse senetleri ile ilgili fiyat davranış bilgilerine ulaşılmıştır.

Araştırmanın fayda çerçevesi çizildiğinde; kümeleme çalışması iki noktada yatırımcılara karar verme süreçlerinde katkı sağlayabilir. İlki benzer kümelerde yer alan hisse senetlerinden biri henüz diğer hisselerde hareket başlamadan öncü olarak bir harekete başlamışsa aynı kümede yer alan diğer hisselerinde eşlik edeceği varsayımıyla yatırımcılar yatırımlarını yönlendirebilirler. Yükseliş durumlarında öncü hisse kadar yükseliş göstermemiş diğer hisseler satın alınarak bu hareketten fayda sağlanabilir ya da düşüş durumlarında öncü hisse senedi düşüşe başladığında yatırımcının portföyünde kümeleme sonucunda aynı kümede yer alan hisse senetlerinden biri veya birkaçı varsa bu hisse senetleri satılarak zarardan kaçınılabilir. Bu bilgiler ışığında kümeleme sonuçları incelendiğinde 30 hisse senedinden 19 tanesinin hem pandemi öncesi hem de pandemi sonrası aynı kümede yer aldığı görülmektedir. Bu kümelenme yukarıda açıklanan strateji çerçevesinde kullanılabilir.

Tablo 12. COVID-19 Öncesi Dönemde ve COVID-19 Döneminde Aynı Kümede Yer Alan Hisse Senetleri

\begin{tabular}{|c|c|c|c|}
\hline Küme 1 & Küme 2 & Küme 3 & Küme 4 \\
\hline ARCLK & GARAN & AKBNK & BIMAS \\
\hline TAVHL & GUBRF & EKGYO & KOZAL \\
\hline TCELL & & EREGL & TUPRS \\
\hline \multirow[t]{7}{*}{ TKFEN } & & HALKB & \\
\hline & & ISCTR & \\
\hline & & KRDMD & \\
\hline & & SISE & \\
\hline & & THYAO & \\
\hline & & VAKBN & \\
\hline & & YKBNK & \\
\hline
\end{tabular}

Örneğin bankacılık sektörünün ağırlıklı biçimde yer aldığı Küme 3’deki hisse senetlerinin birkaçında meydana gelen fiyat hareketlenmesi ipucu olarak kullanılıp kazanç elde etmek için veya kayıplardan kaçınmak için kullanılabilir. Araştırmacılar kümelenme analizine ilave yapacakları nedensellik analizleri ve birliktelik analizleri ile karar vermeyi kolaylaştırıcı verilere ulaşabilir. 


\section{KAYNAKÇA}

Akpınar, H. (2017). Data: Veri Madenciliği Veri Analizi. Papatya Yayınclık.

Aydın, D. (2013). Bankaların 2012 Yılı Sermaye Yeterlilik Rasyolarına Göre Kümeleme Analizi ve Çok Boyutlu Ölçekleme Sonucu Sınıflandırılma Yapıları. Bankacılık ve Sigortacılık Araştırmaları Dergisi, 1(5-6), 29-47.

Baynal, K., Çalış, A. (2016). Kümeleme Analizi İle Bankacılık Sektöründe Satış Stratejilerinin Belirlenmesi. Beykent Üniversitesi Fen ve Mühendislik Bilimleri Dergisi, 9(1), 13-41.

Clatworthy, J., Buick, D., Hankins, M., Weinman, J., Horne, R. (2005). The use and reporting of cluster analysis in health psychology: A review. British journal of health psychology, 10(3), 329-358.

Danacı, T., Koçtürk, O. M. (2017). Türkiye Serbest Bölgelerinin Kümeleme Analizi İle Karşılaştırılması. Celal Bayar Üniversitesi Sosyal Bilimler Dergisi, 15(4), 351-370.

Dogan, B. (2008). Bankalarin Gözetiminde Bir Araç Olarak Kümeleme Analizi: Türk Bankacilik Sektörü Için Bir Uygulama. (Basılmamış Doktora Tezi). Kadir Has Üniversitesi Sosyal Bilimler Enstitüsü Finans ve Bankacilik Bilim Dali, Istanbul.

Eren, H., Ömürbek, N. (2019). Türkiye'nin Sağlık Göstergeleri Açısından Kümelenmesi ve Performans Analizi. Mehmet Akif Ersoy Üniversitesi Sosyal Bilimler Enstitüsü Dergisi, 11(29), 421-452.

Gazel, S., Akel, V. (2018). Borsa İstanbul'da Sektör Sınıflandırmasının Kümeleme Analizi İle Belirlenmesi. Muhasebe ve Finansman Dergisi, (77), 147-164.

Halk Yatırım, “Skor Kart", https://www.halkyatirim.com.tr/skorkart, (07.12.2020).

Karaatlı, M., Altıntaş, E. (2019). Borsa İstanbul İşletmelerinin Veri Madenciliği İle Kümelenmesi-Clusterıng The Companıes Lısted On Stock Exchange Istanbul By Data Mınıng. Mehmet Akif Ersoy Üniversitesi Sosyal Bilimler Enstitüsü Dergisi, 10(26), 871-886.

Matriks Data, "Matriks Veri Terminali", https://www.matriksdata.com/website/bireysel-urunler/matriksveri-terminali, (07.12.2020).

Okumuş, A., Bozbay, Z., Dağlı, R. (2010). Banka Müşterilerinin İnternet Bankacılığına İlişkin Tutumlarının İncelenmesi. Erciyes Üniversitesi İktisadi ve İdari Bilimler Fakültesi Dergisi, (36), 89-111.

Punj, G., Stewart, D. W. (1983). Cluster analysis in marketing research: Review and suggestions for application. Journal of marketing research, 20(2), 134-148.

Ramoni, M. F., Sebastiani, P., Kohane, I. S. (2002). Cluster analysis of gene expression dynamics. Proceedings of the National Academy of Sciences, 99(14), 9121-9126.

Romesburg, C. (2004). Cluster analysis for researchers. Lulu Press.

Rong, C. (2011). Using Mahout for clustering Wikipedia's latest articles: A comparison between k-means and fuzzy c-means in the cloud. In 2011 IEEE Third International Conference on Cloud Computing Technology and Science, 565-569.

Salighehdar, A., Liu, Y., Bozdog, D., Florescu, I. (2017). Cluster analysis of liquidity measures in a stock market using high frequency data. Journal of Management Science and Business Intelligence, 2(2), 1-8.

Şchiopu, D. (2010). Applying twostep cluster analysis for identifying bank customers' profile. Buletinul, 62(3), 66-75.

Turanll, M., Özden, Ü. H., Türedi, S. (2006). Avrupa Birliği'ne Aday ve Üye Ülkelerin Ekonomik Benzerliklerinin Kümeleme Analiziyle İncelenmesi, İstanbul Ticaret Üniversitesi Sosyal Bilimler Dergisi, 5(9), 95-108.

Yılmaz, M., Dağ, O., Kocabıyık, T. (2020). Güncel gelişmeler 1şığında kripto paraların kümelenmesi. Turkish Studies - Economy, 15(3), 1753-1773.

Yu, C. J., Zhang, R. (2014). Research of FCM algorithm based on canopy clustering algorithm under cloud environment. Computer Science, 41(11A), 316-319.

Yuan, C., Yang, H. (2019). Research on K-value selection method of K-means clustering algorithm. JMultidisciplinary Scientific Journal, 2(2), 226-235. 